\title{
Ergonomic Living-Dining Room Design to Enhance Assisted Living for Elderly People in Indonesia
}

\author{
Johanna Renny Octavia ${ }^{a}$ and Maria Stephanie Widjaja ${ }^{b}$ \\ Department of Industrial Engineering, Parahyangan Catholic University, \\ Ciumbuleuit 94, Bandung, Indonesia \\ ajohanna@unpar.ac.id, ${ }^{b}$ maria.stephanie.widjaja@gmail.com
}

Keywords: ergonomic, participatory design, elderly, assisted living, Indonesia

Abstract. The aging population calls for more research efforts towards enhancing assisted living for elderly people living in Indonesia, including ergonomic housing that accommodates their characteristics and needs. This paper discusses a study to provide an ergonomic living-dining room design in elderly homes by applying the participatory design approach with six Indonesia elders. Through interviews and observations, a list of elderly user requirements was defined as a foundation to generate a number of design concepts. Furthermore, one design concept was selected and refined by applying the anthropometry data.

\section{Introduction}

The world population is rapidly aging. The proportion of the world's population over the age of 60 years will be doubled (11\% to $22 \%$ ) between the year of 2000 and 2050 . The number of elderly people, aged 60 years and over, is expected to increase from 605 million to 2 billion by 2050 [1]. Along with the increase of people's life expectancy, the number of elderly people in Indonesia has also significantly increased over the last decades. In 2000, the proportion of Indonesia's elderly population was about $4.6 \%$. By 2020 , it is expected to reach 28.8 million or around $11.34 \%$ of Indonesia's population [2]. The increasing elderly population in Indonesia has brought impact on the living practices in the society. Nowadays, elderly people are more likely to feel the urge of living more independently with limited assistance from other people in their surrounding. They are often required to perform their daily living activities by themselves since they do not always have other people around to help them.

On the other hand, age increase brings deterioration to human bodies. As age increases, physical, psychomotor, sensory and cognitive capabilities of humans decrease [3]. These declines in elderly body functions should be facilitated by daily-living environments and equipments specially designed to meet their specific needs. Designers should consider the characteristics of elderly users to be accommodated in the design of their surrounding and anything within it so that they will find ease, comfort and safety in carrying out their daily-living activities.

In Indonesia, there is a limited number of studies that have investigated the design of ergonomic housing for elderly people such as the design of bathrooms for elderly people living in Indonesian retirement homes [4] and the kitchen design that accommodates the elderly needs in Indonesia [5]. It is encouraged to continue the research effort to investigate other rooms or places in elderly housing. Living room and dining room are the places in elderly homes where they spend most of the time doing their daily activities such as watching TV, reading books, cooking, eating and drinking. However, the furnitures in the living-dining room of most houses are designed for "normal" adult users in mind without considering the elderly characteristics that need to be accommodated. As a result, elderly people may encounter difficulties and discomfort when using the furnitures in the living-dining room. For instance, they may find it uncomfortable to sit on and stand up from a sofa with low height. They may also find it difficult to reach for cutlery utensils placed in high shelves in the dining room. This leads to a situation in which elderly people become dependent on other people's help to assist them in performing their daily living activities. Therefore, it is essential to take into account the characteristics and specific needs of elderly people when designing the livingdining room to enable them to do their activities easily, comfortably and safely. 
This paper presents a study that investigates the needs and requirements of elderly people in Indonesia and provides a design of living-dining room that accommodates their characteristics. We approach the design problem from an ergonomic point-of-view and participatory design. For this purpose, we utilize the Usability, Safety, Attractiveness Participatory (USAP) design model, which involves active participation of elderly people as users when designing products in the phase of needs identification, design concepts generation and prototype evaluation.

\section{Participatory Design}

Participatory design is an antithesis of traditional design in which the designer's expertise what defines the quality of the design. The key attribute of participatory design is the involvement of end users in the design process, from defining user requirements to conducting prototype trials. One of the participatory design techniques is the Usability, Safety, Attractiveness Participatory (USAP) design model [6]. USAP design model is a participatory design technique that involves users directly from the beginning of the design process and requires only a small group of participants ( 2 to 8 users).

According to [6], USAP design model combines the idea of designing by users and designing for users. As can be seen in Figure 1, the application of USAP design model facilitates the collaboration between designers and users in several design phases. End users, in this case elderly people, are directly involved in three phases: (1) acquisition of user needs and design requirements, (2) proposition of conceptual solutions and (3) construction and trial of prototype.

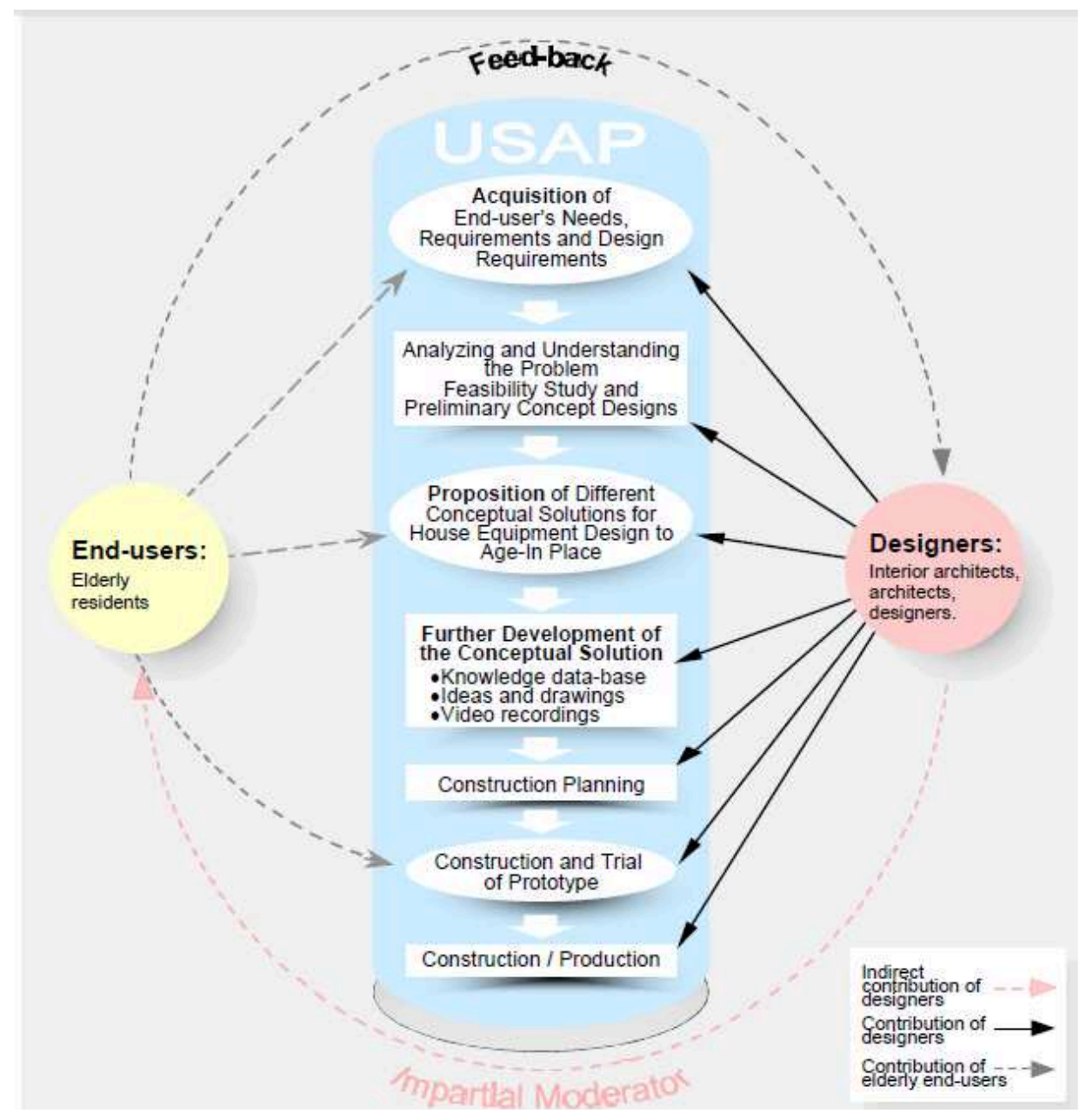

Fig. 1 USAP design model [5] 
We conducted a study to provide a design of living-dining room for elderly people in Indonesia based on the application of USAP design model. In this study, six elderly participants, 3 males and 3 females ranging from 65 to 80 years old, were involved in two sessions: defining user requirements and generating design concepts. The last design stage, construction and trial of prototype, was not the focus of this study.

First Session: Defining User Requirements. The acquisition of elderly user requirements for an ergonomic living-dining room was done through interviews and observations with the participants.

Interviews. The goal from the interviews was to gain an insight of the daily living of participants, especially with regard to their activities and the difficulties experienced in their current living-dining room. From the interviews, several requirements were identified from the participants' comments as shown in Table 1.

Table 1. User requirements identified from interviews

\begin{tabular}{|c|c|c|}
\hline & Identified needs & Participants' comments \\
\hline \multirow[t]{2}{*}{$\begin{array}{l}\text { Living } \\
\text { room }\end{array}$} & Ergonomic sofa & $\begin{array}{l}\text { "The sofa in my living room is too low, so it is hard for me to sit down } \\
\text { and stand up." } \\
\text { "Very difficult for me to stand up from the sofa on my own, I'm already } \\
\text { old and my knee easily hurts." } \\
\text { "I don't feel comfortable sitting in this sofa, I changed the backrest of the } \\
\text { sofa to be more upright because they say it's good for my back." }\end{array}$ \\
\hline & Sofa has a foot support & $\begin{array}{l}\text { "Actually I like sitting with my foot in a relaxed position. Unfortunately } \\
\text { the sofa doesn't have a place where I can put my foot so I usually put my } \\
\text { foot on the coffee table." } \\
\text { "I can't rest my foot while sitting in this sofa." }\end{array}$ \\
\hline \multirow{3}{*}{$\begin{array}{l}\text { Dining } \\
\text { room }\end{array}$} & $\begin{array}{l}\text { The cutlery utensils are } \\
\text { within hand reach }\end{array}$ & $\begin{array}{l}\text { "I never use the upper shelf in the pantry to store things because I can't } \\
\text { reach it." } \\
\text { "It's already difficult for me to reach the lower shelf, the upper shelf is } \\
\text { even more difficult. Still better for me to bend down, although sometimes } \\
\text { it hurts too." }\end{array}$ \\
\hline & $\begin{array}{l}\text { A place to store cutlery } \\
\text { utensils }\end{array}$ & $\begin{array}{l}\text { "I think it would be nicer to have all cutlery utensils in the same place as } \\
\text { where we eat. Now I have the dishes in the kitchen while the spoons and } \\
\text { forks are in the dining room, so I have to walk more." } \\
\text { "I need more effort to get the utensils I need from the kitchen when I want } \\
\text { to eat in the dining room." }\end{array}$ \\
\hline & $\begin{array}{l}\text { A portable furniture to } \\
\text { store small snack }\end{array}$ & $\begin{array}{l}\text { "It is a bit inconvenient that I have to go back and forth to the dining } \\
\text { room every time I need a snack bite like a small bread. It will be easier if } \\
\text { I can have the snack always around me." } \\
\text { "It is too far for me to walk to the dining room to grab small things for } \\
\text { snack while I watch TV in the living room, maybe a small portable table } \\
\text { will help." }\end{array}$ \\
\hline
\end{tabular}

Observations. We observed the participants performing some daily activities in their own living room and dining room. The intention was to identify the interaction of elderly people in the livingdining room and the difficulties they encountered. Figure 2 gives an overview of how an elderly participant moves around and does a number of general daily activities in her living-dining room. As showed in Table 2, we found out several other requirements, which were not yet identified from the interviews, based on the difficulties observed from the participants.

Table 2. User requirements identified from observations

\begin{tabular}{|c|l|l|}
\cline { 2 - 3 } \multicolumn{1}{c|}{} & \multicolumn{1}{c|}{ Identified needs } & \multicolumn{1}{c|}{ Observed difficulties from participants } \\
\hline $\begin{array}{c}\text { Living } \\
\text { room }\end{array}$ & Sofa facilitates easy standing up & - Difficult to stand up from the sofa \\
\hline \multirow{2}{*}{$\begin{array}{c}\text { Dining } \\
\text { room }\end{array}$} & Ergonomic dining chair and table & - Difficult to sit down on the dining chair \\
\cline { 2 - 3 } & Dining chair facilitates easy standing up & - Uncomfortable position while eating \\
\hline
\end{tabular}




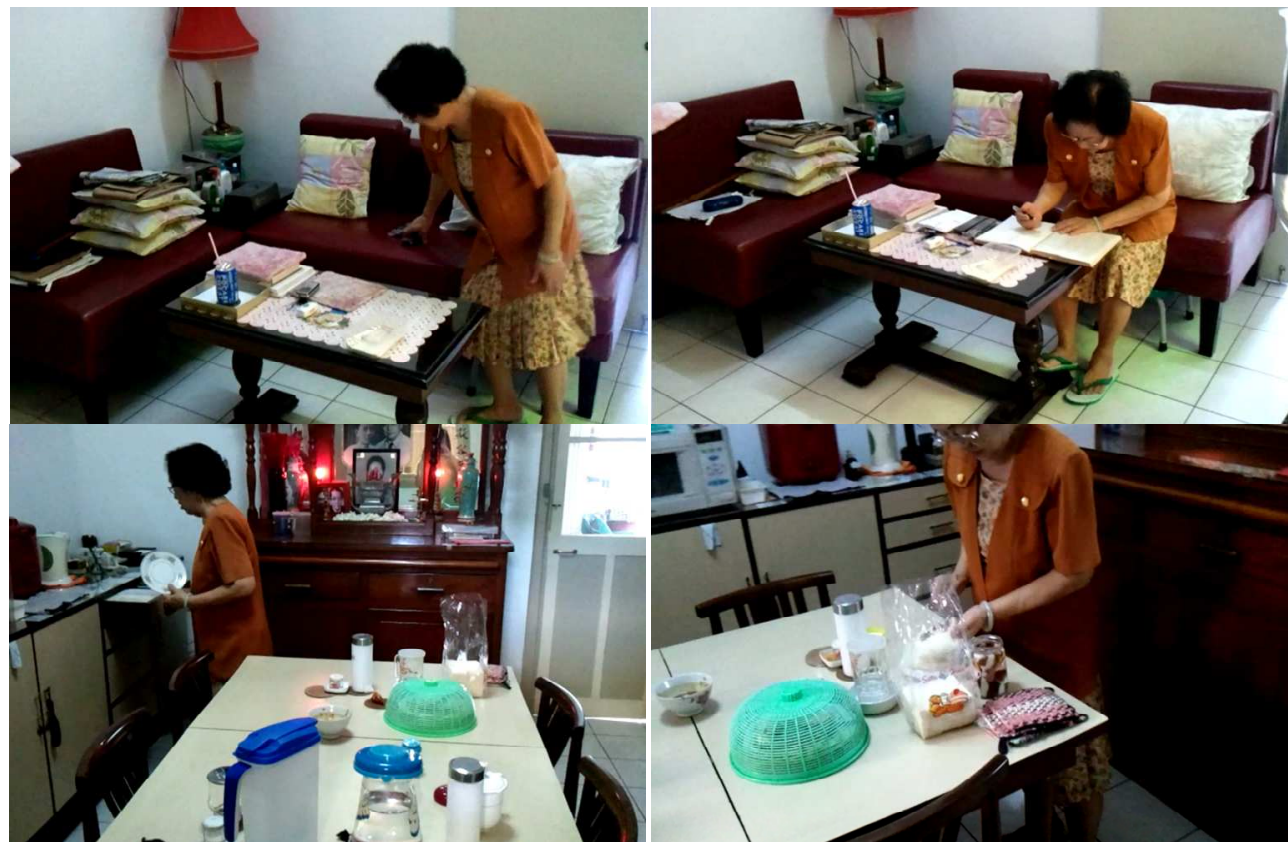

Fig. 2 Observing an elderly participant in her living-dining room

Based on the interview and observation results, a list of elderly user requirements for the design of a living-dining room can be defined as follows:

1. The sofa in the living room is ergonomic, facilitates easy standing up and has a foot support.

2. The chair and table in the dining room are ergonomic and facilitate easy standing up.

3. The dining room is equipped with a place to store cutlery utensils within hand reach.

4. The dining room is equipped with a portable furniture to store small snack.

Second Session: Generating Design Concepts. To meet the defined user requirements, two methods were applied: (1) application of anthropometry data to meet the ergonomic requirements and (2) generation of design concepts to meet the non-ergonomic requirements. These nonergonomic requirements include the need for a foot support, a hand support (to facilitate easy standing up), a shelf (to store cutlery utensils) and a portable table (to store small snack).

Three design concepts were generated for each of the non-ergonomic requirements, but were not discussed in more details in this paper due to the limited space. However as an example, Figure 3 illustrates the design concepts generated in this study to meet the requirement of a shelf in the dining room. All of the design concepts were evaluated with the participants by discussing the positive and negative points of each concept and choosing one selected concept at the end.

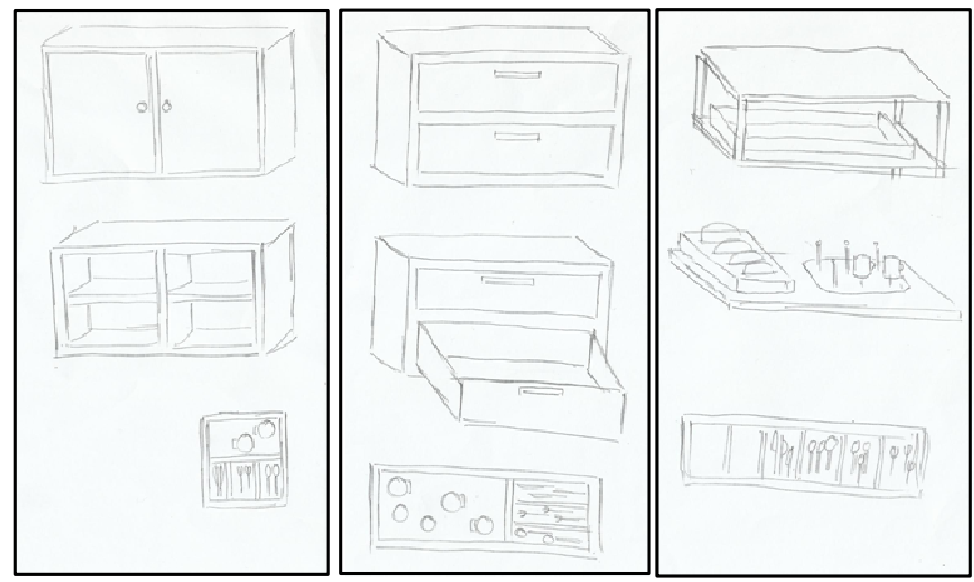

Fig. 3 Design concepts generated to meet the requirement of a shelf in the dining room 


\section{Final Design}

After selecting one design concept for each non-ergonomic requirement, the design concept was further refined in its design by applying the anthropometry data. The anthropometry data used to determine the product dimensions in this study were gathered from fourty elderly people in a previous study [4]. For each selected design concept, a low-fidelity prototype was created to illustrate the final design.

Living Room. Our elderly participants expressed the necessity of an ergonomic sofa which facilitates easy standing up and has a foot support. As showed in Figure 3, the requirement has been answered with a sofa design with foot and hand support to assist elderly in standing up and sitting down on their own.
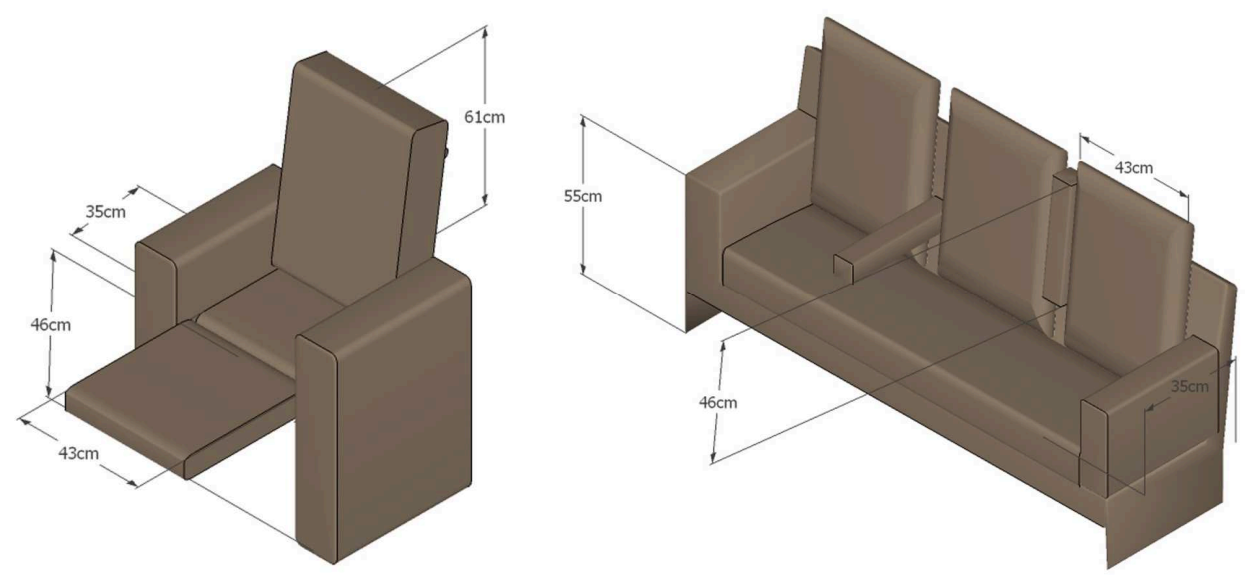

Fig. 3 Ergonomic sofa design for elderly

Dining Room. Several requirements were defined with regard to the dining room and its facilities. First, in line with the requirement of the ergonomic sofa, the elderly participants also identified the need for an ergonomic chair and table in the dining room are ergonomic which facilitate easy standing up. As showed in Figure 4, ergonomic facilities for the dining room such as an ergonomic dining table and an ergonomic dining chair with hand support were designed. Other requirements for the dining room were there should be a place to store cutlery utensils within hand reach and a portable furniture to store small snack. To answer these requirements, an ergonomic shelf and a portable table were designed to be included as part of the pantry in the dining room as showed in Figure 5.
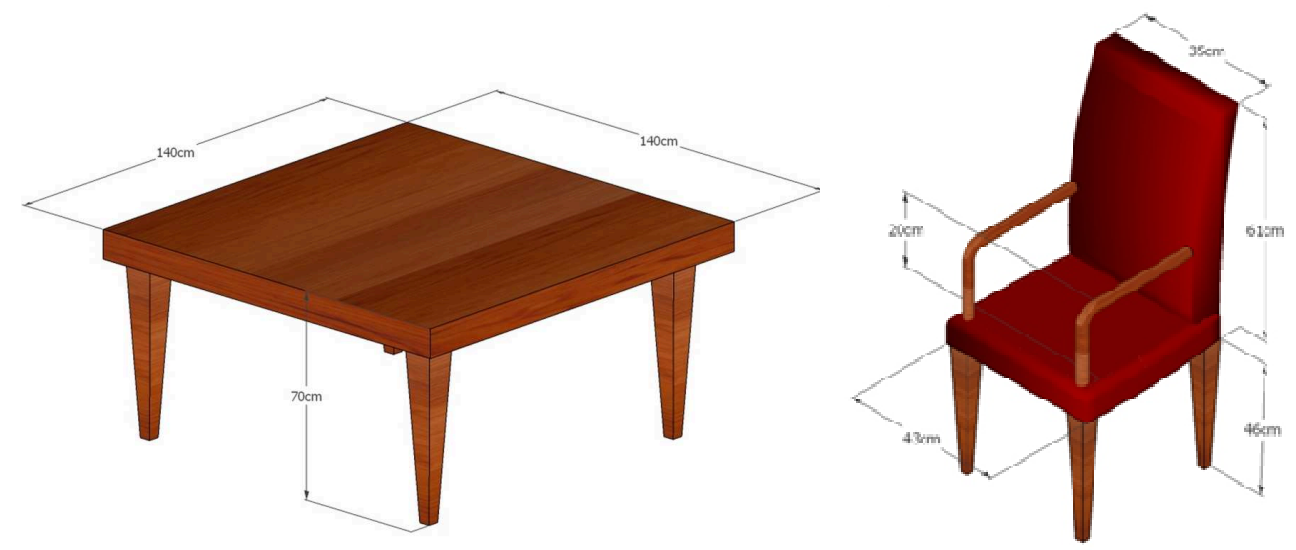

Fig. 4 Ergonomic dining table and chair design for elderly 

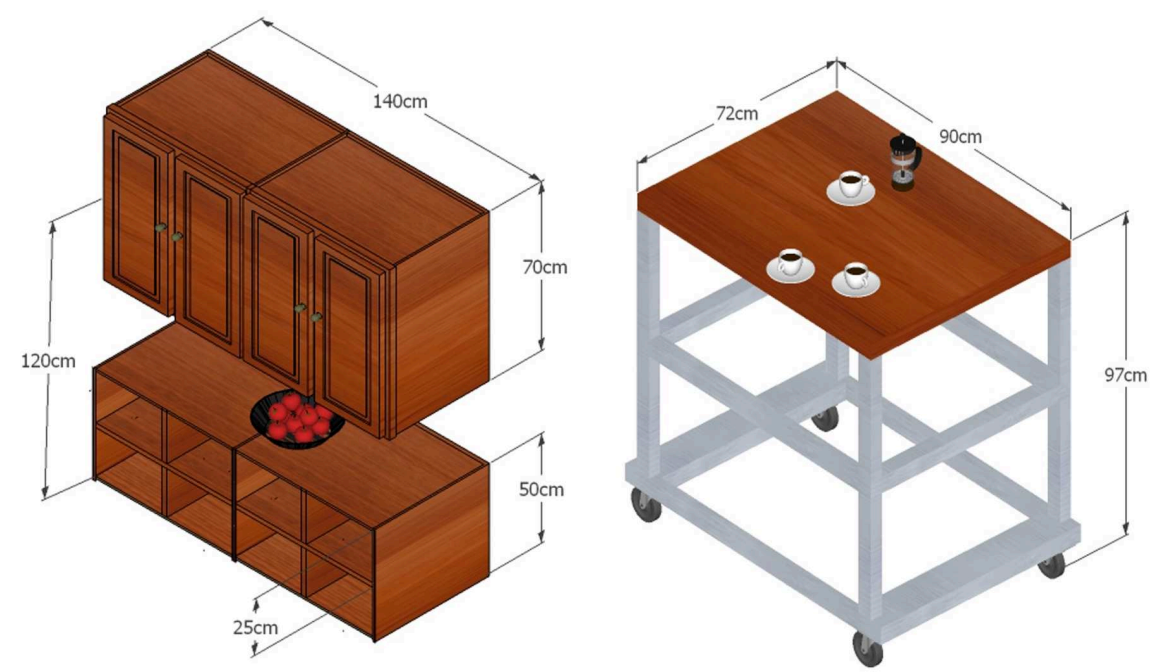

Fig. 5 Ergonomic shelf and portable table for elderly

\section{Summary}

As an effort to enhance assisted living for elderly people in Indonesia, we have provided a design of living-dining room that accommodates their characteristics and specific needs to enable performing their daily activities easily, comfortably and safely. The final design, as shown in Figure 6, was established based on the application of the USAP design model, which involves active participation of six elderly people as representative users in the phase of needs identification and design concepts generation of this ergonomic living-dining room design for elderly.
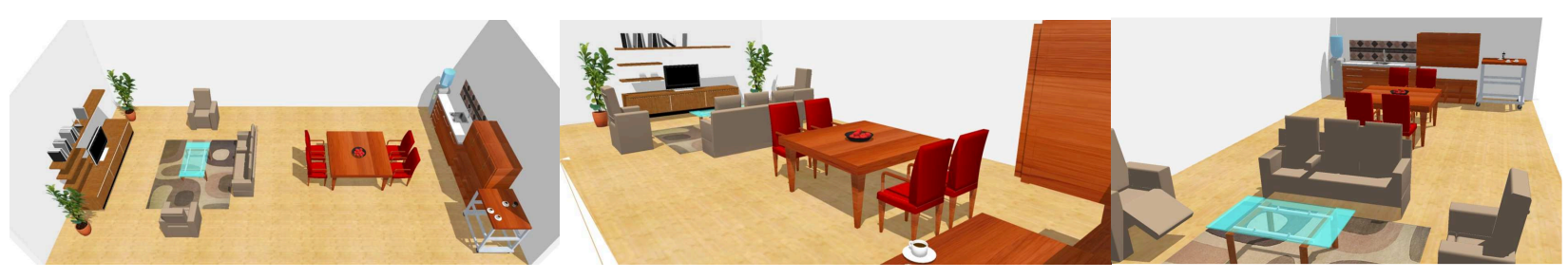

Fig. 6 Living-dining room design for elderly

\section{References}

[1] Information on http://www.who.int/ageing/en/

[2] Information on http://www.bps.go.id

[3] L.P.A. Steenbekkers, C.E.M. Beijsterveldt, Design-relevant Characteristics of Ageing Users, Delft University of Technology, 1998.

[4] R. Setiawan, Design of Bathroom Facilities for Elderly: A Case Study of Salvation Army's Retirement Home, Unpublished thesis. Parahyangan Catholic University, 2007.

[5] R. Hilarius, Application of Universal Design Principles in the Design of a Kitchen for Elderly, Unpublished thesis. Parahyangan Catholic University, 2007.

[6] O. Demirbilek, Involving the Elderly in the Design Process: A Participatory Design model for Usability, Safety, and Attractiveness, Unpublished PhD dissertation. Bilkent University, 1999. 